UDK 528.711

\title{
CLIMATIC VARIABILITY PREDICTION WITH SATELLITE REMOTE SENSING AND METEOROLOGICAL DATA IN THE SOUTH WESTERN NIGERIA
}

\author{
Ebenezer Yemi Ogunbadewa \\ Remote sensing/GIS Unit, Geography Department, Adekunle Ajasin University, \\ Akungba-Akoko, Ondo-State, Nigeria \\ E-mail:ogunbadewa202@yahoo.com
}

Received 05 February 2013; accepted 16 May 2013

\begin{abstract}
Climatic variability affects both seasonal phenological cycles of vegetation and monthly distribution of rainfall in the south western Nigeria. Variations in vegetation biophysical parameters have been known to be a good indicator of climate variability; hence they are used as key inputs into climate change models. However, understanding the response of vegetation to the influence of climate at both temporal and spatial scales have been a major challenge. This is because most climatic data available are derived from ground-based instruments, which are mainly point measurements and are characterized by sparse network of meteorological stations that lacks the spatial coverage required for climate change investigation. Satellite remote sensing instruments can provide a suitable alternative of time-reliable datasets in a more consistent manner at both temporal and spatial scales.

The aim of this study is to test the suitability of one year time series datasets obtained from satellite sensor and meteorological stations as a starting point for the development of a climate change model that can be exploited in planning adaptation strategies. Taking into consideration that rainfall is the most variable element of climate in the study area, rainfall data acquired from five meteorological stations for the year 2006 were correlated with changes in Normalized Difference Vegetation Index (NDVI) derived from Moderate Resolution Imaging Spectroradiometer (MODIS)/Terra satellite sensor for the same period using a linear regression equation. The results shows that rainfall-NDVI relationship was stronger along the seasonal track with $\mathrm{R}^{2}$ ranging from 0.74 to 0.94 , indicating that NDVI seasonal variations can be used as a surrogate data source for monitoring climate change for short and long term scales ranging from regional to global magnitude especially in areas where data availability from ground-based measurements are unreliable.
\end{abstract}

Keywords: predicting; climatic variability; remote sensing, vegetation index.

Reference to this paper should be made as follows: Ogunbadewa, E. Y. 2013. Climatic variability prediction with satellite remote sensing and meteorological data in the South Western Nigeria, Geodesy and Cartography 39(2): 59-63.

\section{Introduction}

Climate plays a major role in vegetation phenological cycles and vegetation growth is functionally dependent on climate. Consequently, a change in biophysical parameter of vegetation canopy implies a change in climate, accordingly vegetation are used as key inputs into climate change models (Friedlingstein et al. 2006; Notaro et al. 2007; Cayan et al. 2008). In recent times vegetation dynamics and their rate of change is accelerating as a result of both natural and anthropogenic factors and the only pointer to the cause of this phenomenal variation in vegetation canopy characteristics is climate change (Costa, Foley 2000; Prentice et al. 2007).

Climate change is when the characteristics and distribution of climatic variables like rainfall, temperature, humidity and wind are at a departure from the expected norms (Giorgi 2006; O'Neill et al. 2006; and Solomon et al. 2007). The effects of climate variability have been felt in many different parts of the world, causing for example, increases in global temperature, melting of permafrost, rising sea-level, alteration of agricultural calendar, changes of vegetation zones 
and increases in heat waves and more allergy attacks on human and animal health (Haeberli, Burn 2002; Stenseth et al. 2002; McMichael et al. 2006; Rosenzweig et al. 2008; Tobin et al. 2008; Mestre-Sanchís, Feijóo-Bello 2009).

These impacts are likely to be an increasing problem in both developed and developing countries in the near future, because there are many levels which still remain uncertain, and there remains a greater need to integrate the biophysical knowledge that currently exists with additional information particularly from data sources that have both spatial and temporal qualities. Presently, climate change studies in this part of the world are faced with the obstacles of developing a proper adaptation framework due to; uncertainty in the levels of risk determination, deficiency of basic long term time series datasets, and downscaling of climate change scenarios to local level. Consequently, there is a need for an appropriate data infrastructure that will incorporate information at both spatial and temporal local scales such as data derived from satellite remote sensing instruments.

Satellite remote sensing is a technique of collecting information about an object/environment without physical contact with the object/environment through electromagnetic spectrum using space platform (Lillesand et al. 1994; Schaepman-Strub et al. 2006; Schott 2007; Schowengerdt 2007).

Vegetation is a good indicator of climatic variability, vegetation greenness has been used in many climate change models using vegetation indices derived from satellite remote sensing instruments (Running, Nemani 1991; Donohue et al. 2007; Danson et al. 2009; Ogunbadewa 2009; Ogunbadewa, Ribeiro Da Rocha 2009). The retrieval of vegetation biophysical parameters from satellite measurements has led to the development of many vegetation indices (Rouse et al. 1974; Goward et al. 1991; Huete et al. 1994; Tucker et al. 2005). The Normalized Difference Vegetation Index (NDVI) is mostly used in remote sensing of vegetation because of its simplicity; it can give a quick qualitative and quantitative estimate of vegetation cover in an image. Expressed mathematically as:

$$
\mathrm{NDVI}=\mathrm{NDVI}=\frac{N I R-\text { red }}{N I R+\text { red }} \text {. }
$$

Range is between -1 and 1 where -1 represents water/bare surface and 1 dense and green vegetation (Rouse et al. 1974).

Aim. The aim of this study is to test the suitability of one year time-series datasets obtained from satellite

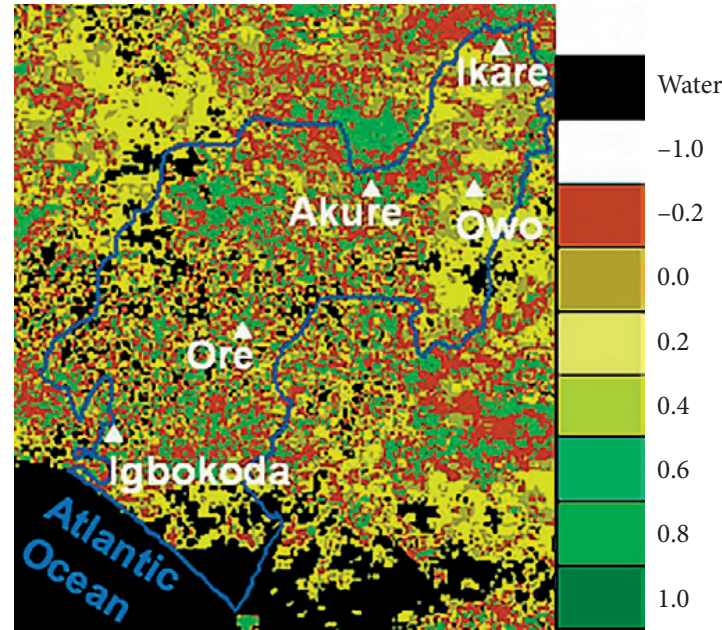

Fig. 1. MODIS-NDVI product of the study site, Ondo-State, Nigeria July 2006

sensor and meteorological stations as a starting point for the development of a climate change model that can be exploited in planning adaptation strategies.

\section{Data and methods}

The dataset used for this study were the MODIS-NDVI product obtained from the National Aeronautics and Space Administration, United States of America (NASA) and rainfall data collected from five meteorological stations (Akure, Igbokoda, Ikare, Ore, and Owo) in Ondo-State, south western Nigeria (Fig. 1).

Subsets of twenty four complete images corresponding to two images per month were extracted covering Ondo-State, south western, Nigeria for a whole year in 2006. The subsets of images were geometrically corrected to the UTM WGS84 Coordinate System using MODIS Re-projection Tool (MRT) and re-sampled to $250 \mathrm{~m}$ pixels. All images were stacked and classified in Erdas Imagine using supervised classification to allow extraction of data on NDVI statistics. NDVI time series datasets were extracted in a single pixel at five different locations in the study sites. NDVI and rainfall data were analysed and correlated for the year 2006 using linear regression equation.

\section{Results and discussion}

The fundamental objective of this study was to find an alternative data source that can be integrated into the existing one for possible improvement towards a better understanding of the magnitude of climatic variability. Taking into consideration that phenological cycle of vegetation is an indicator of climate change and 
rainfall is the most variable element of climate in the study area. Rainfall data from meteorological stations and greenness of vegetation derived from NDVI were correlated using linear regression equation to develop a climate change model (Fig. 2).

The relationship is strong with coefficient of determination $\left(\mathrm{R}^{2}\right)$ ranging from 0.74 to 0.94 , though it varies spatially, with Igbokoda having the highest $\mathrm{R}^{2}$ with the value of 0.94 , Owo 0.91, Akure 0.86, Ikare 0.78 and Ore has the lowest value of 0.74 . The result shows that:

- Increase in rainfall coincides with an increase in NDVI;

- Reflection of climate change is possible from NDVI datasets;

- NDVI datasets can be used for extreme events early warning;

- Model developed from linear regression equations can be used for planning adaptation strategies.

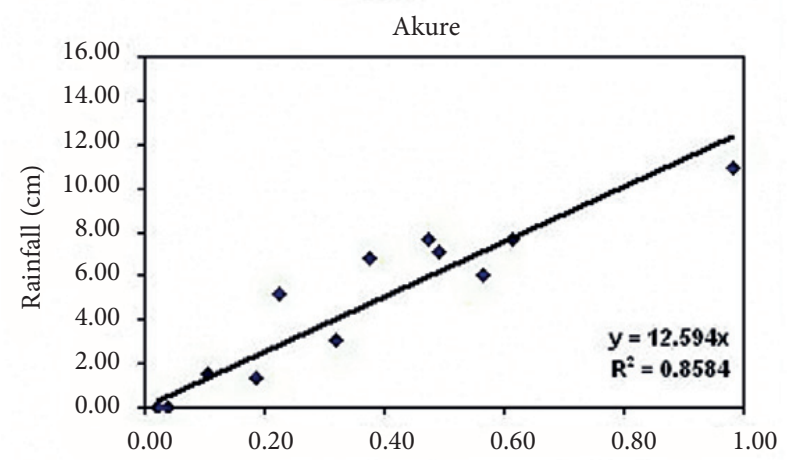

Normalized Difference Vegetation Index (NDVI)

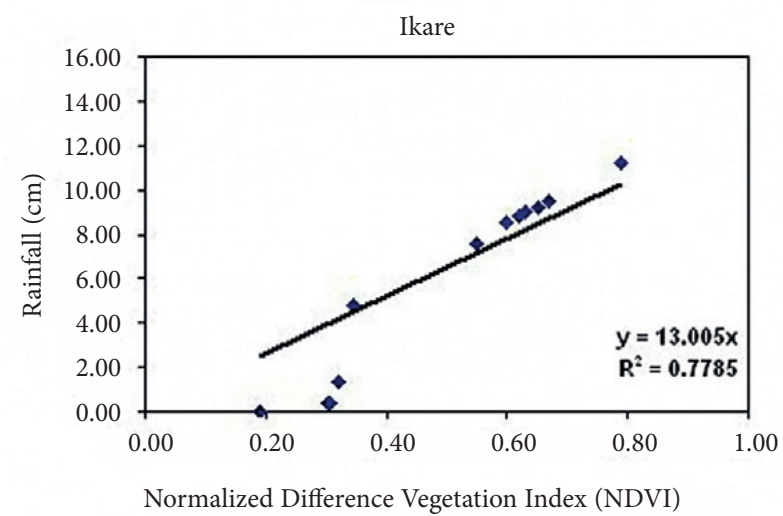

Although it is just one years set of data that was used for this study, showing seasonal fluctuation of both rainfall and NDVI, the high value of $\mathrm{R}^{2}$ shows the potential that the time-series NDVI datasets derived from remote sensing can be a way forward in the direction of advancement in data availability. This study marks the beginning of further investigation and longer term studies; however, the results obtained can still be exploited to develop adaptation strategies for future occurrence of extreme events resulting from climatic variability, even when the study area is experiencing scarcity of meteorological data.
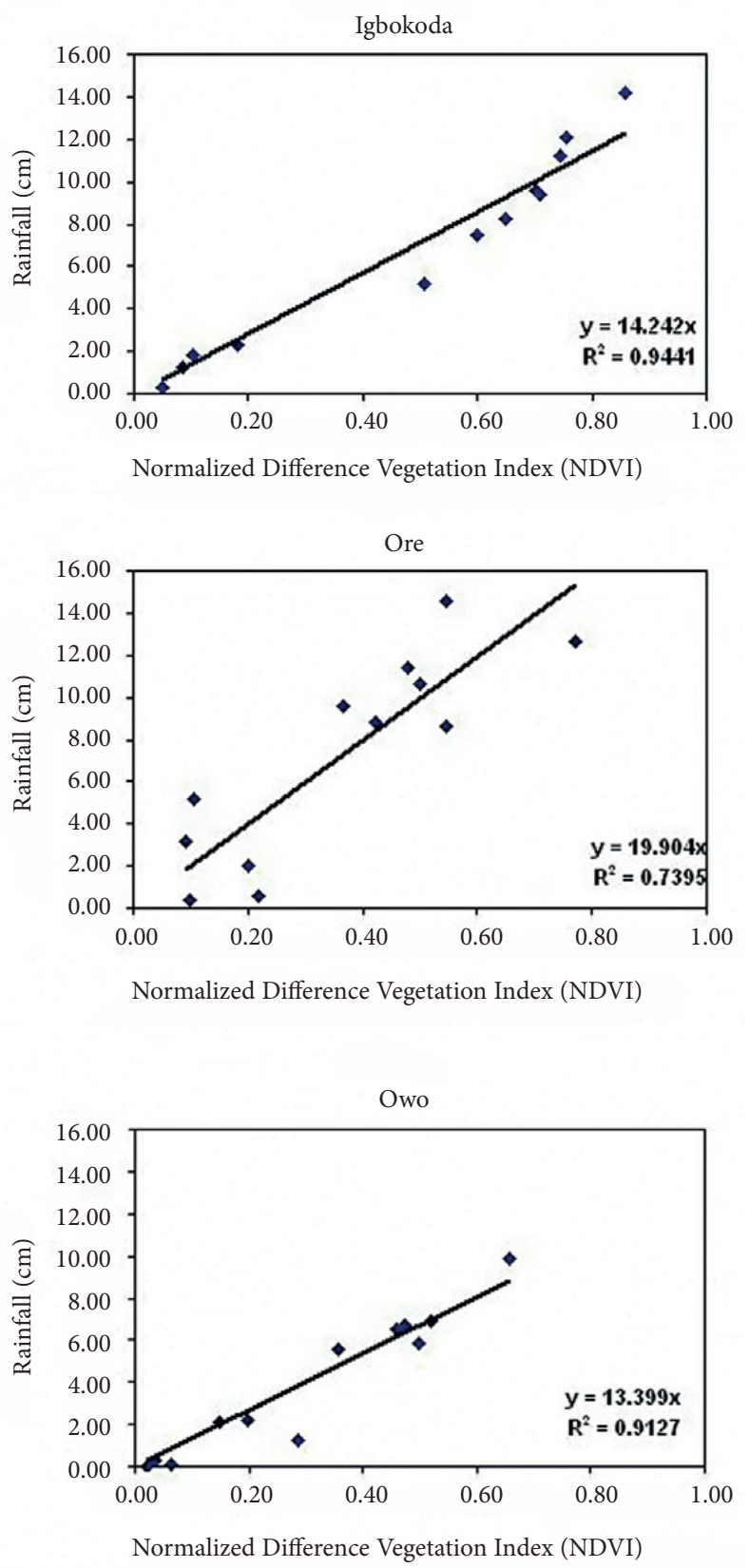

Fig. 2. Linear regressions of rainfall and Normalized Difference Vegetation Indices (NDVI), Ondo-State, Nigeria 


\section{Conclusion and further research}

The results obtained, fulfils the primary aim of this study which was to find an appropriate data source that can be integrated into the currently existing ones with the intention of using an annual dataset as a starting point for longer term studies and further investigation. The result is an improvement in data availability that expresses the magnitude of climatic variability in the study area, even though it is a prediction of intraannual variability but useful in planning adaptation strategies.

There are many challenges: these include; uncertainty in the level of risks involve in the impact of climate change determination, scarcity of basic long term time-series datasets and downscaling of climate change interpretation to local levels. Future work will aim at examining a longer term meteorological data for over 20 years, analysing archived NDVI datasets from satellite sensors with very high spatial and temporal resolution including using multi-sensor remote sensing approach and exploring the possibility of establishing flux towers for eddy covariance measurements.

\section{References}

Cayan, D.; Maurer, E.; Dettinger, M.; Tyree, M.; Hayhoe, K. 2008. Climate change scenarios for the California region, Climatic Change 87: 21-42.

http://dx.doi.org/10.1007/s10584-007-9377-6

Costa, M.; Foley, J. 2000. Combined effects of deforestation and doubled atmospheric $\mathrm{CO}_{2}$ concentrations on the climate of Amazonia, Journal of Climate 13: 18-34.

http://dx.doi.org/10.1175/1520-0442(2000)013<0018:CEOD $\mathrm{AD}>2.0 . \mathrm{CO} ; 2$

Danson, F. M.; Ogunbadewa, E. Y.; Armitage, R. P. 2009. The potential of medium resolution satellite data for monitoring woodland leaf area index in the UK, The Remote Sensing and Photogrammetry Society (RSPSoc), 8-11 September, 2009. Leicester, UK, 141-144.

Donohue, R. J.; Roderick, M. L.; Mcvicar, T. R. 2007. On the importance of including vegetation dynamics in Budyko's hydrological model, Hydrology and Earth System Sciences 11: 983. http://dx.doi.org/10.5194/hess-11-983-2007

Friedlingstein, P.; Bopp, L.; Rayner, P.; Cox, P.; Betts, R.; Jones, C.; Von Bloh, W.; Brovkin, V.; Cadule, P.; Doney, S. 2006. Climate-carbon cycle feedback analysis: results from the C4MIP model intercomparison, Journal of Climate 19: 3337-3353. http://dx.doi.org/10.1175/JCLI3800.1

Giorgi, F. 2006. Climate change hot-spots, Geophysical Research Letters 33(8): L08707.

http://dx.doi.org/10.1029/2006GL025734

Goward, S. N.; Markham, B.; Dye, D. G.; Dulaney, W.; Yang, J. 1991. Normalized difference vegetation index measurements from the Advanced Very High Resolution Radiometer, Remote Sensing of Environment 35: 257-277.

http://dx.doi.org/10.1016/0034-4257(91)90017-Z
Huete, A.; Justice, C.; Liu, H. 1994. Development of vegetation and soil indices for MODIS-EOS, Remote Sensing of Environment 49: 224-234.

http://dx.doi.org/10.1016/0034-4257(94)90018-3

Haeberli, W.; Burn, C. 2002. Natural hazards in forests: glacier and permafrost effects as related to climate change, in R. C. Sidle (Ed.). Environmental Change and Geomorphic Hazards in Forests, IUFRO Research Series 9: 167-202.

Lillesand, T.; Kiefer, R.; Chipman, J. 1994. Remote Sensing and Image Interpretation. New York: John Wiley \& Sons.

McMichael, A.; Woodruff, R.; Hales, S. 2006. Climate change and human health: present and future risks, The Lancet 367: 859-869. http://dx.doi.org/10.1016/S0140-6736(06)68079-3

Mestre-Sanchís, F.; Feijóo-Bello, M. 2009. Climate change and its marginalizing effect on agriculture, Ecological Economics 68: 896-904. http://dx.doi.org/10.1016/j.ecolecon.2008.07.015

Notaro, M.; Vavrus, S.; Liu, Z. 2007. Global vegetation and climate change due to future increases in $\mathrm{CO}_{2}$ as projected by a fully coupled model with dynamic vegetation, Journal of Climate 20: 70-90. http://dx.doi.org/10.1175/JCLI3989.1

O’neill, B.; Crutzen, P.; Grübler, A.; Duong, M.; Keller, K.; Kolstad, C.; Koomey, J.; Lange, A.; Obersteiner, M.; Oppenheimer, M. 2006 Learning and climate change, Climate Policy 6: 1-6. http://dx.doi.org/10.3763/cpol.2006.0639

Ogunbadewa, E. Y. 2009. Evaluating medium resolution satellite data for monitoring seasonal vegetation dynamics, in $P h D$ thesis, University of Salford, UK.

Ogunbadewa, E. Y; Ribeiro Da Rocha, H. 2009. An investigation of variation in vegetation canopy with hemispherical photography and satellite data, in M. Bindi, G. Brandani, A. Dessì, C. Dibari, R. Ferrise, M. Moriondo (Eds.). Impact of Climate Change on Natural and Agricultural Ecosystem. Italy, Firenze: University Press, 215-223.

Prentice, I.; Bondeau, A.; Cramer, W.; Harrison, S.; Hickler, T.; Lucht, W.; Sitch, S.; Smith, B.; Sykes, M. 2007. Dynamic global vegetation modeling: quantifying terrestrial ecosystem responses to large-scale environmental change, in J. P. Canadell, D. Pataki, L. F. Pitelka (Eds.). Terrestrial ecosystems in a changing world. Springer, Berlin, Heidelberg, New York, 175-192. http://dx.doi.org/10.1007/978-3-540-32730-1_15

Rosenzweig, C.; Karoly, D.; Vicarelli, M.; Neofotis, P.; Wu, Q.; Casassa, G.; Menzel, A.; Root, T.; Estrella, N.; Seguin, B. 2008. Attributing physical and biological impacts to anthropogenic climate change, Nature 453: 353-357. http://dx.doi.org/10.1038/nature06937

Running, S. W.; Nemani, R. R. 1991. Regional hydrologic and carbon balance responses of forests resulting from potential climate change, Climatic Change 19: 349-368. http://dx.doi.org/10.1007/BF00151173

Rouse, J. W.; Hass, R. H.; Schell, J. A.; Deering, D. W. 1974. Monitoring vegetation systems in the Great Plains with ERTS, in Proceedings of the Third Earth Resources Technology Satellite-1 Symposium. Greenbelt. 3010-317.

Schott, J. 2007. Remote Sensing: the Image Chain Approach. USA, Oxford: Oxford University Press.

Schowengerdt, R. 2007. Remote Sensing: Models and Methods for Image Processing. San Diego: Academic Press.

Schaepman-Strub, G.; Schaepman, M. E.; Painter, T. H.; Dangel, S.; Martonchik, J. V. 2006. Reflectance quantities in optical remote sensing-definitions and case studies, Remote Sensing of Environment 103: 27-42.

http://dx.doi.org/10.1016/j.rse.2006.03.002 
Solomon, S.; Qin, D.; Manning, M.; Chen, Z.; Marquis, M.; Averyt, K.; Tignor, M.; Miller, H. 2007. Climate Change 2007: the Physical Science Basis. Cambridge: Cambridge University Press.

Stenseth, N.; Mysterud, A.; Ottersen, G.; Hurrell, J.; Chan, K.; Lima, M. 2002. Ecological effects of climate fluctuations, Science 297: 1292. http://dx.doi.org/10.1126/science.1071281

Tobin, P.; Nagarkatti, S.; Loeb, G.; Saunders, M. 2008. Histori$\mathrm{cal}$ and projected interactions between climate change and insect voltinism in a multivoltine species, Global Change Biology 14: 951-957.

http://dx.doi.org/10.1111/j.1365-2486.2008.01561.x

Tucker, C. J.; Pinzon, J. E.; Brown, M E.; Slayback, D. A.; Pak, E. W.; Mahoney, R.; Vermote, E. F.; El Saleous, N. 2005. An extended AVHRR 8-km NDVI dataset compatible with MODIS and SPOT vegetation NDVI data, International Journal of Remote Sensing 26: 4485-4498.

http://dx.doi.org/10.1080/01431160500168686
Ebenezer Yemi OGUNBADEWA. Dr at the Remote sensing/ GIS Unit, Geography Department, Adekunle Ajasin University, Akungba-Akoko, Ondo-State, Nigeria. Ph +2347033285361, email: ogunbadewa202@yahoo.com

Ebenezer Yemi Ogunbadewa, PhD: He is presently a senior lecturer in remote sensing (RS) and geographical information systems (GIS) at Adekunle Ajasin University, Akungba Ondo-State, Nigeria. He obtained B. Sc Geography (University of Ilorin), M. Sc Geography and Planning (University of Lagos) in Nigeria, UN/SIDA International certificate in RS and GIS (University of Stockholm) Sweden and PhD in RS and GIS (University of Salford), UK. He has got many international academic awards and publications in reputable books and scholarly journals. 